\title{
ATTITUDES TOWARDS CATCHING AND KILLING THE YAMABIRU (LAND LEECH) IN THE TENRYU AREA, JAPAN
}

\author{
Satoshi Watanabe \\ Faculty of Humanities, Seikei University, Tokyo, Japan. \\ E-mail: s.watanave@gmail.com \\ Citation: Watanabe, Satoshi. 2019. Attitudes Towards Catching and Killing The Yamabiru (Land \\ Leech) in The Tenryu Area, Japan. J. Asian Rur. Stud. 3(2): 130-144
}

\begin{abstract}
Recently, yamabiru, or land leeches (Haemadipsa zeylanica japonica), have proliferated in prefectures across Japan. Since it is unlikely that they will disappear from the living spaces, fields, and forests in which humans live and work, people living in the new contact zones have devised methods to coexist with them. The field research was conducted in 2017 and 2018 in C Township in the Tenryu area. Like many rural areas in Japan, C Township is facing the challenges of depopulation and ageing, and is home to a group of residents who aim for local revitalization. The participatory observation of leech-catching, an activity practiced by the group members who dare to use their hands to kill yamabiru instead of chemicals, provides several implications regarding ethical attitudes and the role of the human body. This paper argues that the members do not behave as victims suffering from the damage caused by yamabiru and do not kill them out of anger or discomfort. Instead, by behaving as an assailant and seeking out the concrete feeling of killing by direct contact, the members attempt to control their disastrous impact on other creatures and the environment. This behavior invites us to pay closer attention to the role of the human body and of bodily interaction as a sensory tool to coexist with other creatures in the Anthropocene, an era full of risks and uncertainty in which it is difficult to recognize which species humans have driven to extinction.
\end{abstract}

Keywords: Anthropocene; Haemadipsa zeylanica japonica; Yamabiru (land leech); Japan

\section{Introduction}

This case study aims to explore what life is like alongside the land leech, called the yamabiru in Japanese. How are people in rural areas of Japan coping with their relatively new neighbor? Focusing on the circumstance in which people are killing the yamabiru and the manner in which they kill, this study examines a contemporary effort to coexist with a troublesome creature whose existence was changed by coming into contact with humans and other living and non-living things.

The Anthropocene, a new epoch during which humans became an earth-changing force that caused numerous unprecedented risks and unintentional consequences, is both the era of the sixth mass extinction (Barnosky et al., 2011, Ceballos et al., 2015, Heise, 2016) and the era in which many non-human species have changed or expanded their habitats due to ongoing environmental and social pressures (Simberloff, 2013). As a result, new contact zones between humans and non-human species have developed around the world. Some of these species are harmful or poisonous to humans (Hotez, 2016, Bulled and Singer, 2016), which is why it is of utmost importance to capture what 
is happening in these contact zones and to accumulate knowledge on the emerging practices that enable coexistence with these creatures. This case study aims to contribute to this need.

Recently, yamabiru (Haemadipsa zeylanica japonica) have proliferated in prefectures across Japan. According to the Yamabiru Research Group (YRG), the species is found in 34 of 47 prefectures in Japan (Yamabiru Research Group, 2017a). Their expanding habitat has become increasingly evident countrywide since the beginning of the twenty-first century. However, scholars focusing on rural studies in Japan have focused very little on this new issue, namely, the life that is emerging alongside this parasite. It is probable that the only exception in rural studies is Watanabe (2018). Watanabe examines how rural people are trying to coexist with the yamabiru. Coexistence in the context of this study means living with the possibility of direct contact in a shared place, without creating clear-cut borders to separate human and nonhuman domains (Watanabe, 2018: 111). Although the study elucidates the diversity of the relationships that residents in rural areas could potentially create with the yamabiru, beyond that which is typical of a mere binary host-parasite or kill-killed relationship, its main focus is not on the circumstance in which people are actually killing the yamabiru.

The recognition that human activities are accompanied by numerous risks and unintentional consequences might cause people to lose their sense of direction: it is hard to know what we are doing. In this paper, we explore how a group of local people in a rural area of Japan are trying to kill the yamabiru. They are intentionally using their hands to kill them instead of spraying expellant on the ground. The study would argue that the reasoning behind this local activity is to become familiar with and feel what they are killing with their own body. This leech-catching is a small activity to recapture control of what they are doing and how they are living with in an age filled with uncertainty. Leech-catching provides the implications of our contemporary practice of learning how to live alongside other creatures.

\section{Multi-species studies}

In recent years, we have borne witness to an increase in multi-species studies. Multi-species studies is a field that is characterized by a loose interdisciplinary alignment that maintains the idea that human lives and ways of life cannot be described separately from those of other living organisms; it focuses on how human lives, lifeways, and accountabilities form entangled, interwoven patterns of living and dying in multi-species relationships (van Dooren et al., 2016: 2). The works related to this discipline focus on the dynamics of entanglement that position beings as, for example, predator and prey, parasite and host, and researcher and study subject (van Dooren et al., 2016: 3).

Relationships with creatures that are referred to as "unloved others" (Rose and van Dooren, 2011: 1) or "negative aesthetic charisma" (Lorimer, 2015: 48) have also been the focus of multi-species studies. The research related to "awkward creatures" could "demonstrate the ways in which vulnerability, violence, and death are part of on-going, generative engagements with nonhuman others, rather than simply being negative elements that can be repressed, ignored, or solved" (Ginn et al., 2014: 121). 
Rethinking our concept of "unloved others" prompts us to realize our history that is filled with violence. Rigby (2011) clearly showed the complex dynamics of the relationships between people and the bongong moth (Agrotis infusa) in Australia. Rigby describes the violent history of the moths, which were isolated from the indigenous peoples' practices and other creatures and treated as pests or mere exotic food in the context of economic cosmopolitanism since the colonialization era (for more on the process of the creation of "pests" or "trash animals," see Dower, 1986, Setoguchi, 2009, and Nagy and Jonson, 2013). By writing the history of the bongong, Rigby tries to portray the insect as "an advance guard of sorts, nudging us towards the long overdue inauguration of a more inclusive parliament: one, that is, which would seek to rule in the interest, not just of human citizens, but of all beings" (Rigby, 2011: 92).

Based on the fundamental perspective of multi-species studies, this paper concentrates on a specific moment of violence, or the killing of "unloved others." In the face of the Anthropocene or the so-called sixth mass extinction, the need to regain an awareness of our unprecedented violent impact on other creatures and seek the better means of controlling it is undoubtedly increasing. This study attempts to participate in, describe, and examine the scene in which violence is perpetrated against "unloved others," and explore how those who actually conduct the violence perceive their activity. The case examined in this paper elucidates the contexts in which this form of killing is enmeshed in the contemporary world. Although it is almost impossible to imagine a world without violence, we can expand our imagination on how our violence should be carried out.

\section{Yamabiru in Japan}

A monk is walking on a mountain road. He notices something falling down onto his hat. He shakes his head, but nothing falls down from his hat. He has no choice but to grab it with his fingers. It looks like a sea-cucumber. Soon, blood begins to trickle from the finger that the sea-cucumber was attaching itself to. In his astonishment, he notices that the "mountain-cucumbers" appeared on his elbow, neck, and in his clothes too. He also notices that they were hanging on every single branch of the trees. They began to pour down fiercely like a rain shower.

Koya Hijiri, one of the most famous Japanese classic fantasy novels, written by Kyoka Izumi, is also famous for its beautiful and uncanny passage on this "mountaincucumber" summarized here in a not so beautiful manner". This "mountain-cucumber" is the yamabiru. Since the Japanese land leech does not reportedly climb trees, this passage is probably fantasy. Nevertheless, the "real" yamabiru is as surprising as the tale of the monk because when we enter places with high habitat density, they appear from the ground as water springs forth from a pond ${ }^{2}$.

\footnotetext{
${ }^{1}$ Shigekazu Tani and Sueko Ui, the members of the Yamabiru Research Group, made the author pay attention to the description of the yamabiru in Koya Hijiri.

2 There is a method to estimate the habitat density, referred to as the "five-minute-human trap method." A researcher stands on several points in one block for five minutes and counts all the yamabiru lured to him or her (generally, the yamabiru in $3 \mathrm{~m}^{2}$ is supposed to be lured to a person), and calculates the arithmetic average of the points. If the average is over 1.0, the chances of blood sucking increase. If the average is more than 10.0, everyone hesitates to enter the zone (Yamabiru Research Group, 2009, p. 2). For example, the author has experienced habitat
} 
For this novelist, the world of leeches is what comes after the world of humans is over. While a monk entered the world of leeches in Koya Hijiri, this world of leeches is, however, approaching the world of humans in contemporary Japan. In some areas, the yamabiru suck the blood of humans passing through mountain roads, vegetable fields, gardens, backyards, and even in houses and taxis.

The yamabiru is a leech that lives on the ground, especially under fallen leaves in humid areas. Their size ranges from approximately one centimeter ( 0.39 inches) to six centimeters ( 2.36 inches). The yamabiru is aware of humans approaching based on body temperature, $\mathrm{CO} 2$ emissions, and vibrations. It moves like a measuring worm, and the most active season is from May to October. When a yamabiru attaches itself to one's skin, it tears open a point with its small teeth and waits for the blood to flow into its open mouth while it secretes the anticoagulant hirudin which has an anesthetic effect and prevents the blood flow from stopping. According to the YRG, thus far, it is unlikely that the yamabiru have become vectors for infectious diseases (Yamabiru Research Group, 2017b). However, one case has been reported of a sixty-two-year old woman who exhibited serious symptoms with a high fever (Yamamoto, et al., 2005: 1161).

The first place where yamabiru caused problems was a mountainous area called Gojome in Akita Prefecture, in the northern region of the main island of Japan. It was around the late 1970s when forest workers began to complain about the damage caused by yamabiru. According to a report by the Gojome local forestry office in 1980, 147 forest workers out of $158(93 \%)$ had experienced the damage. The reported symptoms included not only ordinary ones such as "red swelling," "unceasing blood flow," and "itchiness," but also "fever," "suppuration," and "vertigo." The report especially expresses concern over "vertigo" (Kamiya, et al., 1981: 11-12).

Another report describes how severe this situation was: "there was a serious recruiting problem because forestry workers hated to work in yamabiru habitats." In the Gojome area, the yamabiru then expanded into farmlands and residential areas. It was a "threatening situation for everyday life" (Akita prefecture, 1997: 1). A local high school teacher, Kennosuke Nagata, also mentioned the "mental damage" because "it is exhausting that we must heed warnings for 24 hours of whether the uncanny mollusks that are difficult to notice are hiding around the house, whether they are attaching themselves to clothes that are being hung outside, or whether they are crawling on the floor of the bathroom" (Nagata, 1997: 45).

The official report of Akita prefecture listed four cases of "territory infringement," such as, "In July of 1995, a yamabiru that had already sucked blood was found on the fourth floor of the prefectural office. There was a guest from Gojome area several hours ago," or "In June of 1994, a researcher of yamabiru found two yamabiru searching for animals in his garden. They were probably brought there with edible wild plants from their habitat." After the list, the reporter states without hiding his surprise, "there are many cases where yamabiru were found on our bodies or the handles of a car on the way back from habitat research, even though we scrutinized our bodies carefully and

density research in a block whose average was 9.8, and it was impossible to hinder the yamabiru from climbing his body. There is also a record in Akita prefecture that there was a zone whose average was almost 50.0 in 1996 though the research method was slightly different (Akita prefecture, 1997, p.16). 
captured and killed all the found yamabiru before getting into the car (Akita prefecture, 1997: 33-34)."

The main vector of yamabiru is not, however, humans. A DNA analysis of the blood in the yamabiru indicates Sika deer, serow, and wild boar as the main vectors (Sasaki and Tani, 2008: 27). A statistical estimation shows approximately 2.49 million deer in 2012, but only around half a million in 1989 (Ministry of the Environment, 2015a). The habitat area in 2014 was almost 2.5 times larger than that in 1978 (Ministry of the Environment, 2015b). As Watanabe (2018) mentioned, since the 1960s, many rural areas have faced rapid ageing and depopulation, and many farmers and their children have abandoned farming and moved to the cities. As a result, numerous areas where wild animals can hide and live emerged near the living places of humans. An increasing number of abandoned farmlands transformed into bush or forests, enabling wild animals to approach and live in rural areas. In addition, the conifer forests where postwar forestry policy in the 1950s and 1960s eagerly converted bare land to respond to the increasing demand of the woods, were abandoned, becoming a dark space with less biodiversity. Here, overgrown branches block the sunlight from penetrating the forest floor, and dark forests can no longer provide food for the increasing number of wild animals (Watanabe, 2018: 111).

Encountering the yamabiru is thus a historical phenomenon. Wild animals took advantage of postwar social-natural changes in Japan, carrying the yamabiru from the deep mountains to the countryside. Especially Akita, Gunma, Kanagawa, Chiba, Shizuoka, and Hyogo prefectures are famous for having many places where the population of yamabiru is large. The list is still growing longer, though the habitat density and the distance from residential areas of each case must be different from each other and there must be cases that are rediscovered or where the yamabiru are temporarily brought in.

There are a few chemicals available to avoid having your blood sucked: expellants and repellants that can be purchased in drugstores or on the internet. Nevertheless, it is not realistic to assume that the yamabiru would completely disappear from human residential areas, so people must consider how to cope with this problem. The places where the world of the yamabiru approaches ours are also the ones where people should seriously think about what humans are allowed to do to construct the world of humans. Our bodies and the current formation of the society and economy in Japan inevitably lure the yamabiru. In Koya Hijiri, the monk encountered a bewitching woman after going through the forest of leeches. Her body with its mystic powers inevitably lures men and changes them into beasts. Notwithstanding, she had to continue living with those beasts.

\section{Method}

The field research was conducted in 2017 and 2018 in C Township. C Township is in the Tenryu area of Shizuoka prefecture in the Tokai region of central Japan and faces the Pacific Ocean. It is a mountainous town with a population of 2,173 people as of 2017. The percentage of elderly people over 65 years of age is $57.29 \%$.

Like many rural areas in Japan, C Township is facing the challenges of depopulation and ageing, and is home to a group of residents who aim for local revitalization. According to the group's website, their purpose is to develop the township into a place 
that people will enjoy visiting. They have taken this approach because increasing the population of $\mathrm{C}$ Township, in which there are only a few places to work, is too difficult to achieve. The members, consisting mainly of approximately twenty people over 60 or 70 years of age, are former forest workers, farmers, and retirees who hope to research one hundred mountains and hills around $\mathrm{C}$ Township, and create and maintain a hiking trail accompanied by lists of viewpoints and large, old trees. The depopulation and ageing process has forced the members of the group to consider how the objects and landscapes with which they interact will be inherited by the next generation.

The field research mainly consisted of two types of interviews. The author participated in some of the group's activities. The author searched for, picked up, and killed the leeches with the group members. During these activities of participant observation, the author discussed the yamabiru with the group members without using a structured list of questions. The topics the author discussed ranged from the members' life history and the history of $\mathrm{C}$ Township, to the strategies of tourism and rural revitalization. Along with this conversational style, the author interviewed five people who embodied central roles in the group, using the format of a semi-structured interview. This interview included the topics related to the history and future plans of the group. Note that pseudonyms are used for most interviewees' names and districts in the description.

\section{Results and Discussion}

\subsection{What is leech-catching?}

The leech-catching, referred to as "hiru-tori," is conducted by the members of the group described above. The activity itself is quite simple. A group of people go to the habitat of the yamabiru and catch the lured yamabiru with chopsticks and tweezers. The caught yamabiru are thrown into a jar containing salts that kill them. The people count all the killed yamabiru and record the number. That is all.

Generally speaking, if we talk about expelling the yamabiru, the method is usually spraying expellant. In particular, luring the yamabiru by walking around or breathing heavily and then spraying the expellant directly onto the leech is reportedly effective. Of course, the people conducting leech-catching know this. They intentionally chose not to use chemicals and to use their hands.

In the past, the yamabiru had a different local name, "Jito mushi (Jito worm)," called so after a district of $\mathrm{C}$ Township, which means the yamabiru used to be confined to a small mountainous area. However, up until the 1980s, the yamabiru started to expand their habitat to all the mountains and farmlands. Nowadays, the residents can see the yamabiru even in their farmland and garden.

The leech-catching started in 2013 when some hikers reported that there were yamabiru on the hiking trail that the group was maintaining. There was also a rumor that the yamabiru had caused a car accident: a hiker driving home was astonished at a yamabiru that suddenly appeared on his or her hand, and that led him/her to steer in the wrong direction. The yamabiru problem was seen as a threat to the group's project of creating a good town to visit. They were concerned about the damage it may cause to the image of $\mathrm{C}$ Township. 
The members have, therefore, concentrated their efforts on the places that are famous for their landscapes or where local school children have their field trips. According to a table created by the members, leech-catching is conducted on an average of twelve days a year and 2,357 yamabiru were caught and killed in total from 2013 to 2016. Nowadays, leech-catching is famous to the extent that local newspapers have affirmatively written some articles about it. According to the members, however, there are also cynical responses to the activity among the people of the $\mathrm{C}$ Township: they think it is meaningless because the population of yamabiru is overwhelmingly large. When the author was conducting an interview in a local restaurant, the restaurant owner, a friend of the interviewee, cut into the conversation and said, "The guys (yamabiru) never disappear even if these guys (the members) make a great effort." The interviewee denied this, "No, no, no. Leech-catching works. On the day immediately after leechcatching, we aren't obviously bitten (December 10.2017)."

The goal is not the extermination of yamabiru. They want to decrease the habitat density to the extent that visitors do not get bitten. Ms. A told the author that it was a great pleasure when no children got bitten during a field trip when visiting an area where leech-catching had taken place several days before (August 29, 2017). Another member also points out that their goal is "kyozon-kyoei" (coexistence and coflourishing). According to him, since the yamabiru have already increased to the extent that it is impossible to eliminate them, the members have no choice (August 29, 2017).

It is natural to wonder why the members are not using chemicals or whether they have considered its use. One reason is environmental risk. During the interview (August $29,2017)$, the representative of the group said, "When we were working as forest workers, we sometimes killed the yamabiru one by one with expellant. But we never sprayed chemicals on the ground. We sprayed each yamabiru's body as it was attaching to our arms and feet. That was the most effective method." Another man continued, "We discussed spraying kalium chloride, but we were afraid deer would come to lick it and drop the yamabiru. Spraying chemicals on the ground might have a bad effect on the ecosystem. If we tried to exterminate them, we were not able to know what would happen."

They use salt instead of an expellant because salt is much "cheaper" and free from "health concerns." However, the question that still remains is why they dare to catch and collect the dead yamabiru. They could simply sprinkle the yamabiru with salt and leave the dead yamabiru on the ground as many hikers $\mathrm{do}^{3}$. The four members repeatedly explained the reason: "Touching them directly teaches us what the yamabiru are like, and killing them with our hands makes us experience how the killing actually happens," "We have to feel what we are killing with our hands, otherwise we cannot know what we are doing to the environment," "We can count how many yamabiru we have killed because we use our hands," or "Look at this table (mentioned above). This point shows an obvious decline in the population of yamabiru. We want to feel this kind of change, so we collect the yamabiru." In order to understand these testimonies, we must examine how the leech-catching is conducted.

\footnotetext{
${ }^{3}$ In Kanagawa prefecture, for example, some local governments or organizations place salt boxes on hiking trails for hikers and tourists.
} 


\subsection{The leech-catching day}

The day after a rainy day is considered to have the best conditions for leech-catching because the high humidity makes the yamabiru move actively which makes them easy to find. The members once tried to conduct leech-catching on a rainy day. However, they were not able to distinguish the yamabiru from fallen leaves moving due to the rain.

Ms. A is a core member of the leech-catching group and is in her sixties. In the group, leech-catching is considered as an activity led by women. There are loose gendered divisions of labor in the group: men mainly climb the mountains and maintain the trails and the women conduct leech-catching. At the beginning of leech-catching, Ms. A said that in the past, she had been really scared of the yamabiru and just able to "play the role of screaming when she noticed the yamabiru." Now she describes herself as "skillful."

Ms. A's skill is based on the experiential knowledge that she acquired during leechcatching. In an interview, she explained this with the help of a piece of writing, summarizing what she had discovered.

- The yamabiru seem to hate Japanese horse chestnut leaves. On the contrary, they are often under the fallen leaves of cedar trees.

- The strength of the sucker can pick up a stone.

- We cannot catch the yamabiru when it is curling its body. This stance is defensive. When it aims at blood sucking, it swings its body. This is our chance. But we have to get accustomed to catch it with tweezers.

- Tweezers with the yamabiru should be inserted directly into a bin filled with salt. It is not easy to detach it from tweezers and hands.

- There is never a time when the yamabiru live evenly in one place. When we are walking, there is a point where the yamabiru gather together densely, then there is a point without any, and again a point with many yamabiru.

- On the forest road, the yamabiru usually come from the lower side, so we walk on the upper side of the road if we want to avoid the yamabiru.

- There is a local proverb that says, "In the leech road, you should go first. In the snake road, you should go last." I don't think this is correct. The proverb says that the first person awakens the yamabiru and the second and third one get bitten, which is different from snakes that bite at the first encounter. In reality, the order has nothing to do with who gets bitten.

- We have to put on white clothes because it makes it easier to see when the yamabiru have attached themselves to each other's bodies.

- We usually put on rubber boots and block openings with packaging tape, and then have a piece of gauze with salt water around the boots. However, we should be cautious with the fold in the packaging tape before going into a house in case yamabiru are hiding there.

- It seems that the yamabiru have boot preferences. Some types of rubber boots seem to lure the yamabiru more than other. It might have something to do with body temperature. Nevertheless, the yamabiru have a preference.

- We must not use umbrellas, and rain coats are also dangerous. The yamabiru hide themselves in the folds and wait to suck your blood (August 29, 2017). 
This is a list of empirical knowledge that Ms. A has constructed from her encounters with yamabiru. There is also an art to killing the yamabiru. By using her hands, she came to know how the yamabiru behave and how strongly it tries to resist her in its attempts to defend itself. This knowledge is of course temporary and should be modified as she gains more leech-catching experience ${ }^{4}$.

On the morning of the tenth of September in 2017, leech-catching was conducted in a forest trail from a residential area to a shrine on the peak of a mountain. This trail has been maintained by members of the group. A famous sweets company in a large city in Shizuoka prefecture was planning to have a field trip there several days later (they use some of the crops in C Township).

The participants were three women, two men, and the author. Before going to the trail, the members gave the author chopsticks and a small glass jar that was filled halfway with salt. Ms. A spread the salt from her bin onto a piece of paper to show me. The salt had remained as it was when she had last used it in July. The salt was brown and there were many black grains in it. They were the dead yamabiru. They were like hard rubber.

We walked slowly in single file up along the trail from eight o'clock that morning (Fig. 1). Since it seemed to have rained in the night, Ms. A told us that the conditions were good. This turned out to be true. The yamabiru soon appeared when we started marching. Later, she confessed with a smile that she kindly brought along repellant for the author, but she decided to make him experience the leech-catching as it truly was. Nobody uses repellant when leech-catching.

Regardless of it being intentional or unintentional, our pace was slow, since someone always shouted "here!" and squatted down to pick up a yamabiru crawling on the ground. They did so while counting, "twenty, twenty-one, and twenty-two," etc. The members also monitored each other's bodies and frequently communicated with each other: "Yours is a big one!" or "This is very small," "Thank you for climbing my boots (Fig. 2). It made you easy to catch, thank you, thank you," and "Give me the one attaching itself to your back." Although the yamabiru resisted, once it was inserted into a jar, it immediately dropped down.

The author also took a turn being a "decoy" by walking in the front of the group. Since he had little experience with habitat density research, it was not easy to distinguish the yamabiru from the fallen leaves. It took a particularly long time to identify the small ones that were less than one centimeter in length. It was also difficult to pick up the yamabiru since they became stickier due to the salty chopsticks. When having trouble in picking up a curling one or when one was encroaching on his socks, another one was seen approaching nearby or starting to climb his body. The author could do nothing but catch them one by one and often had to ask other members for help.

\footnotetext{
${ }^{4}$ The discoveries Ms. A made should be both the same as and different from those made by people who also frequently encountered the yamabiru. For example, it is probable that many people agree with the strength of the sucker, however, the determination of which side of the forest road is inhabited by more yamabiru is controversial. The clothes worn to avoid blood sucking is also a controversial topic. Of utmost importance here is that the experience, landscape, history, and the forms of the encounters are inscribed in experiential knowledge.
} 
A short time into the leech-catching expedition, one of the group members told the author to smell the jar. A strange, nasty, fishy smell was coming from it. After placing more than twenty yamabiru in the jar, you could smell it just from opening the jar. He saw that some already looked like black seeds while others were secreting a thick jellylike substance and were crawling on those seeds as if trying to escape from the salt. The author shook the jar to ensure that the salt covered all the yamabiru. The salt turned black and green.

In areas where the yamabiru population was not so large, the group members asked the oldest women to tell them how the villagers used the trail in the past when there was no paved road. They also learned the names of plants and birds and picked up Japanese horse chestnuts. They also discussed the yamabiru a lot: "This area has a lot of yamabiru probably because of the cedar leaves," "I think Japanese horse chestnut has tannic acid. That makes the yamabiru go away," and "Wild boar obviously came here. That's why there were so many yamabiru. The vector is not only deer but also wild boar. What about bears? There are signs of bears coming here." While talking, a woman was bitten. She laughed and said "when I saw the blood, I thought it came from my nose." She treated the injury with salt and an antihistaminic drug.

At noon, the other members who did not participate in the activity were supposed to come to the shrine on the peak to pick us up. The members and the author noticed that they were still only halfway to their goal at eleven o'clock. They decided to increase the pace. A member said, "We don't have to catch all the yamabiru. We should do what we can." They started to walk faster than before and often ignored the continuously appearing yamabiru. After arriving at the parking area of the shrine, the members checked each other's backs while mentioning how many yamabiru they encountered on the trail. Even though they checked thoroughly, the yamabiru appeared in the car from their boots.

Finally, the members calculated all the killed yamabiru (each member says how many s/he caught by his/her own count), recorded the total number, and photographed the jars and chopsticks (Fig. 3). On that day, 1,044 yamabiru were caught and killed. It was a "new record" since one member had started participating in the activity. It was surprising because they thought that the number of yamabiru in $\mathrm{C}$ Township was relatively small in 2017 . A woman joked, "It is sad as well when I can see only a small number of yamabiru." Ms. A also smiled, "Yes, I wanted you (the author) to see the yamabiru because you came to $\mathrm{C}$ Township far away from home. I was correct to choose this trail. I thought there would be a large population."

As mentioned above, the group's goal is not the extermination of yamabiru. During their lunchtime, the members not only talked about the next area they would work on and the improvement that needed to be made to their clothes to defend their bodies, but also joked with each other: "The yamabiru that avoided being picked up must be feeling relieved now," "Yep, they succeeded in navigating through the disaster!" They never expressed that they were sorry for not being able to kill all the yamabiru.

There is, nonetheless, a temptation to try more "effective" extermination techniques. For example, during the leech-catching, when the author told the members about the activities in other places using expellant and flame throwers to burn the eggs of yamabiru in winter, they responded, "that must be more effective!" The author was also frequently asked if there are good chemicals to eliminate all the yamabiru from the 
mountain. One of the group's founders even mentioned burning the whole mountain, though he knew it was not feasible (October 12, 2017). Extermination is always an option regardless of whether it is applicable or not.

However, in 2017, the group decided not to spray chemicals on the ground again. This decision was made when the local tourism bureau sprayed a chemical on the trail leading to an old castle, the most popular tourist attraction in $\mathrm{C}$ Township. The group members had conducted leech-catching there, but the bureau was unaware of that fact. When the members went to the area, they were surprised that many of the plants in that area had withered. Although it was not easy to scientifically prove the connection between this phenomenon and the chemical, the members decided to continue their current method of leech-catching. Ms. A told the author that their intention was to decrease the environmental risk as much as possible and that they must still "know how many yamabiru we killed in order to know what we are capable of doing and what kind of influence we are having on the ecosystem, and also to know about the yamabiru itself by killing with our hands" (December 15, 2017). She also added that the members of the group wanted to continue this activity as long as possible. The members are ageing. They are searching for and anchoring their activities in the context of an ongoing dialogue between the yamabiru and their own ageing bodies.

\section{Conclusion}

Focusing on the circumstance in which people are killing the yamabiru, as well as the method used to kill it, this study attempts to examine a contemporary effort towards coexistence with a troublesome creature whose life was changed by the interaction between human activities and other living and non-living things. It is true that the members conducting leech-catching believe that tourism and farming are negatively affected by the yamabiru and, if possible, they want to remove all of them from the fields in which they are working (of course, they also know that the complete removal of this creature is impossible). However, they also recognize that the yamabiru was brought to the area in the midst of a process of socioeconomic change and that human activities have had a serious impact on the environment. The recognition of this risk and the unintentional consequences of human activity have caused the members to focus their actions carefully.

In short, leech-catching is an attempt to become familiar with the yamabiru, a creature that they must kill but also live alongside. Familiarizing themselves with the smell of the yamabiru, its responses, and its desire to live, as well as counting the dead yamabiru, helps the group members understand their own actions and the impact they inevitably have on this creature. Additionally, as several testimonies demonstrated, counting the dead yamabiru is especially important both to acknowledging their agency and achievement with joy and to realizing their impact on and responsibility toward the environment.

The simple spraying of chemicals does not allow them to physically sense how many yamabiru they kill and the nature of what they are killing. Therefore, leechcatching is maintained by their constant effort to restrain themselves from using more "effective" killing methods. It is important to note that the group members do not perceive this constraint as a negative aspect of their work. 
In conclusion, the attitude held by the members is their attempt to be an assailant. The members do not behave as victims suffering from the damage caused by yamabiru and do not kill them out of anger or discomfort. They instead behave as assailants to maintain their connection with the sensation of killing the yamabiru, to remember its response and smell, and to prevent themselves from forgetting these sensations. In doing so, the members attempt to take responsibility for their disastrous impact on the environment and other creatures. For this process to work, they need to recognize that they are the ones harming the creatures they live alongside.

An important implication of leech-catching is that it invites us to reconsider the roles our senses, such as seeing, touching, and smelling, play in our acquisition of knowledge from interactions with other creatures. The members of this study use their bodies as sensory tools as often as possible. They do not simply attempt to understand the physical form and nature of the yamabiru; they wish to capture how it lives and dies in their hands. To behave as an assailant, they have to directly experience the feeling of killing yamabiru.

Although sensation is often deceptive, we cannot ignore that the senses are important tools with which we may anchor ourselves in the world as living, physical beings. In the Anthropocene, or the era of the sixth mass extinction, it is not easy to remember which species and how many we have driven to extinction, or that we have caused them to become extinct at all. The leech-catching activities of this group casts doubt on this contemporary lifestyle. It is a small, tactical effort to impose some constraint on a life of uncertainty and shows us that this constraint can be acquired through the process of anchoring ourselves by our bodily interactions with other mortal creatures.

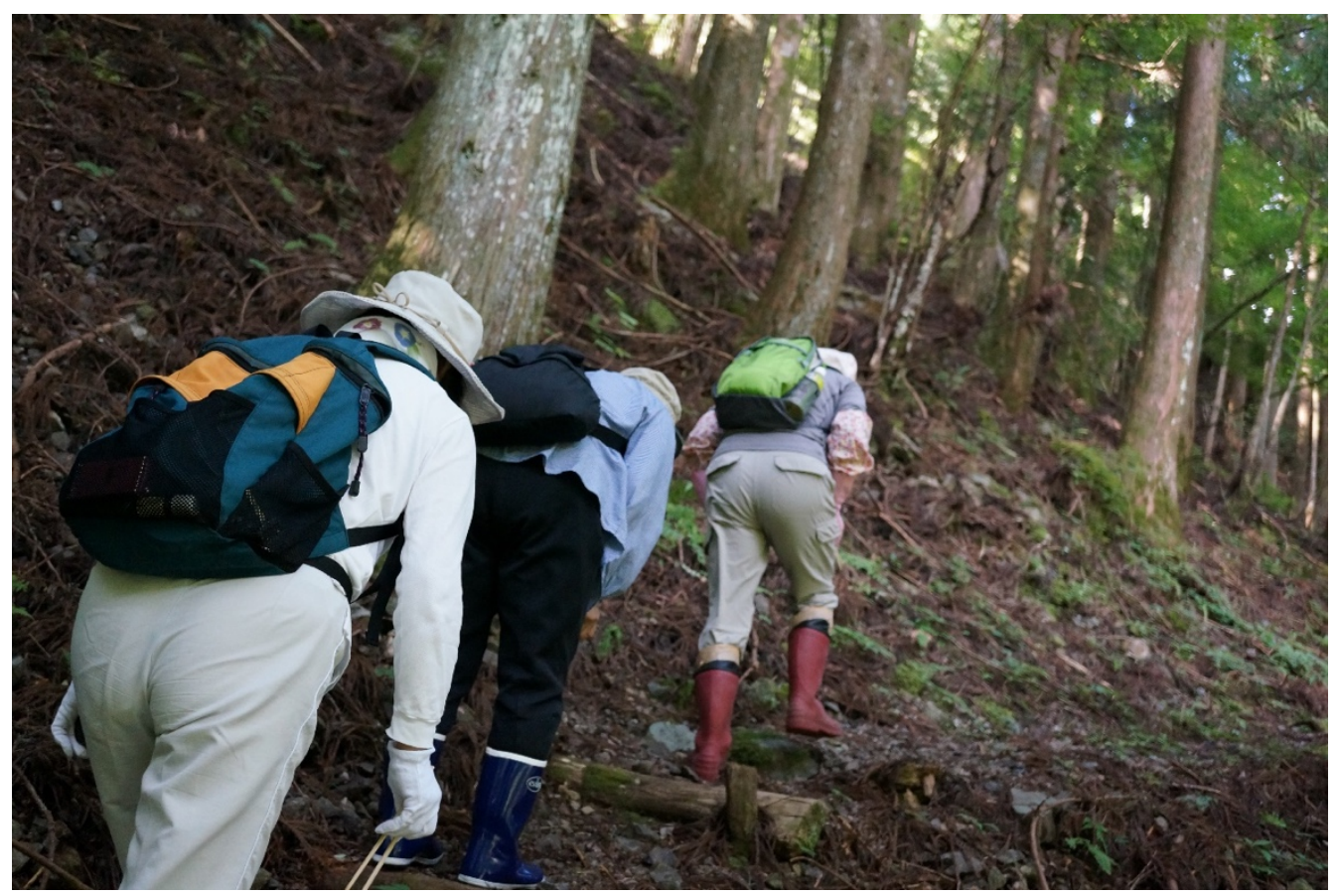

Fig. 1. Slowly walking up the hill to search for the yamabiru. Photo by Satoshi Watanabe. 


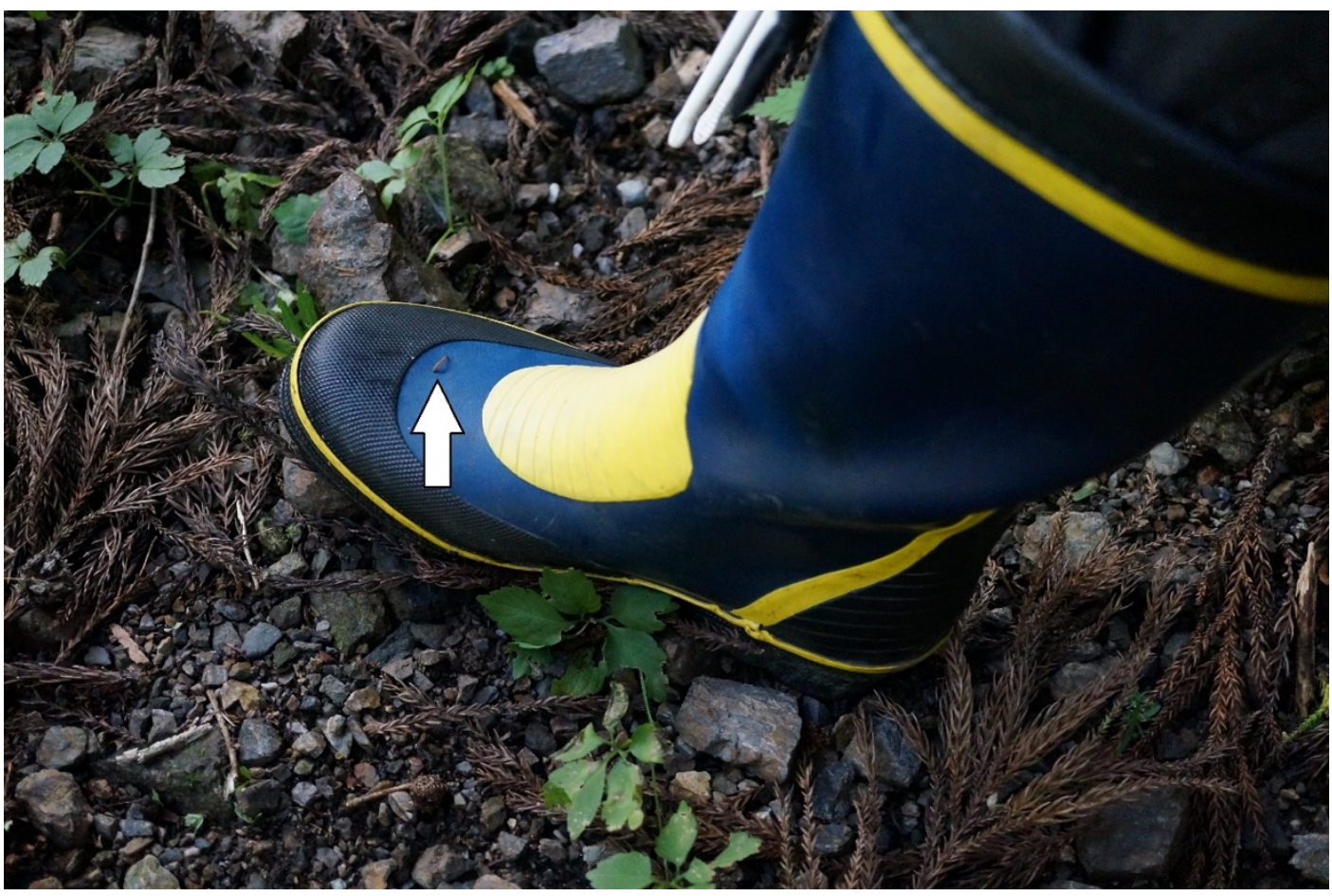

Fig. 2. A small yamabiru attaching itself to the boot of a group member. Photo by Satoshi Watanabe.

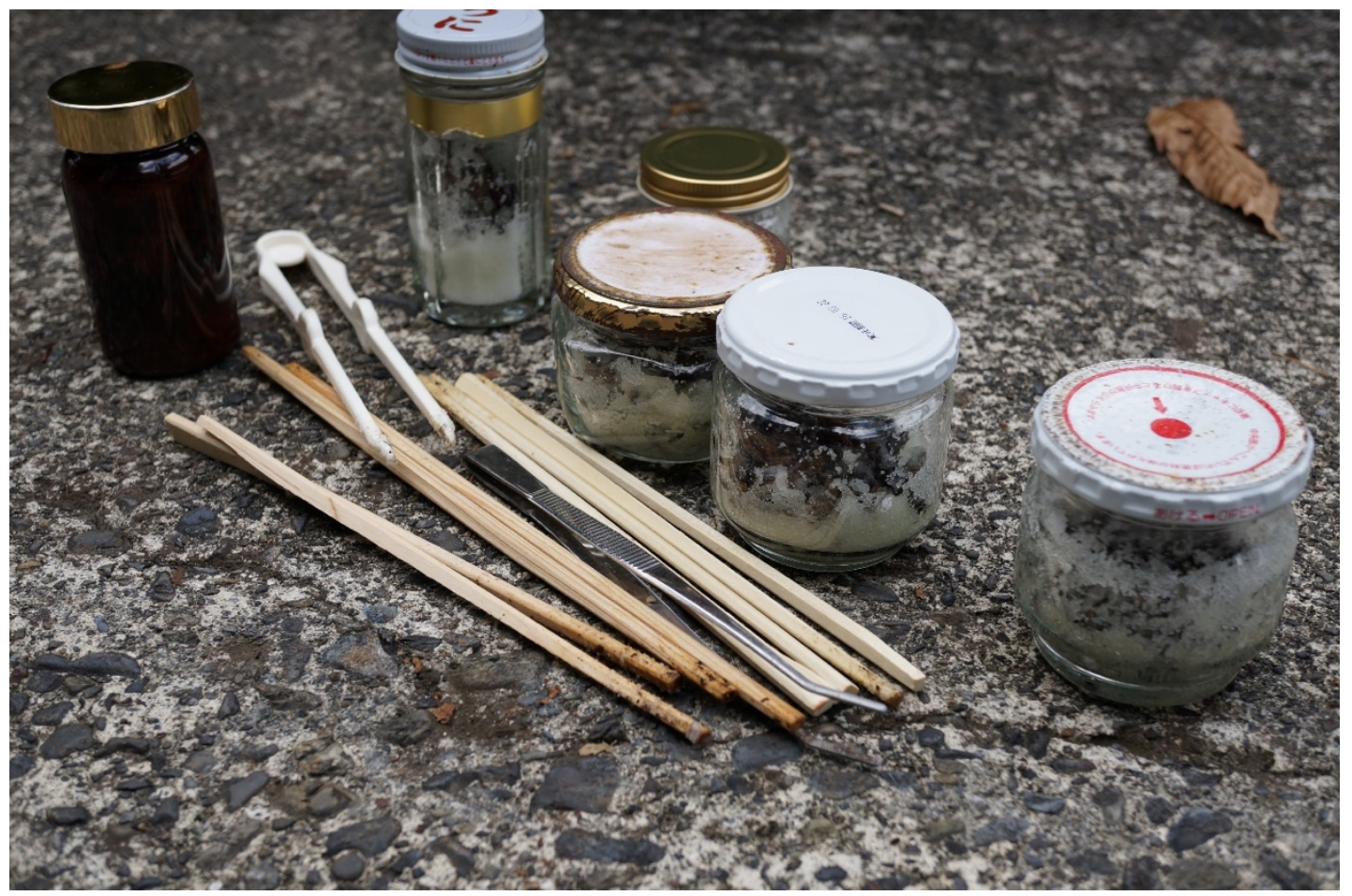

Fig. 3. The jars, tweezers, and chopsticks for leech-catching (the black shapes in the jars are the dead yamabiru). Photo by Satoshi Watanabe. 


\section{Acknowledgements}

This research received funding from the Toyota Foundation Research Grant Program (D16-R-0439). The author would also like to express his appreciation to Shigekazu Tani, Hideki Nakata, Yusuke Ashida, Hiroyuki Kaneko, Yoshikazu Kitajima, and Mayumi Sato for their advice.

\section{References}

Akita prefecture, 1997, Akita no Yamabiru: Seitai to Bojo, Yamabiru Higai Boshi Sougo Taisaku Jigyo Hokokusho (Yamabiru in Akita: The Life and Pest Control: the Report of the Integrated Project for Preventive Approach to the Yamabiru Damage), Akita: Akita prefecture.

Barnosky, A. D., Matzke, N., Tomiya, S., \& Wogan. G. O. U., 2011, Has the Earth's Sixth Mass Extinction Already Arrived?, Nature 471(7336), pp.51-7.

Bulled, N. \& Singer, M., 2016, Health and the Anthropocene: Mounting Concern about Tick-borne Disease Interactions. In Singer, M. ed., A Companion to the Anthropology of Environmental Health, Hoboken, NJ: Wiley-Blackwell, pp. 483516.

Ceballos, G., Ehrilich P. R., Barnosky, A. D., García. A., Pringle, R. M., \& Palmer, T. M., 2015, Accelerated Modern Human-induced Species Losses: Entering the Sixth Mass Extinction. Scientific Advances 1(5), e1400253.

Dower, J. W., 1986, War without Mercy: Race and Power in the Pacific War, New York: Pantheon Books.

Ginn, F., Beisel, U., \& Barua, M., 2014, Flourishing with Awkward Creatures: Togetherness, Vulnerability, Killing. Environmental Humanities 4, pp. 113-123.

Heise, U. K., 2016, Imagining Extinction: The Cultural Meanings of Endangered Species, Chicago: Chicago University Press.

Hotez, P. J., 2016, Neglected Tropical Diseases in the Anthropocene: The Cases of Zika, Ebola, and Other Infections. PLoS Neglected Tropical Diseases 10(4), e0004648.

Kamiya, H., Ishida, K., Ishigouoka, K., Yamashita, K., Oka, M, 1981, Yamabiru no Seisoku Doko no Kaimei to sono Bojo Taisaku ni kansuru Hokokusho (The Report on the Life of the Yamabiru and Its Pest Control). Akita: The Forestry Office of Akita.

Lorimer, J., 2015, Wildlife in the Anthropocene. Minneapolis: University of Minnesota Press.

Ministry of the Environment, 2015a, Tokeishuho ni yoru Zenkoku no Nihonjika oyobi Inoshishi no Kotaisusuitei to ni tsuite (On the Estimation of the Population of Sika Deer and Wild Boar Using Statistical Methods). Retrieved May 12, 2017 from http://www.env.go.jp/press/files/jp/26914.pdf

-———, 2015b, Zenkoku no Nhonjika oyobi Inoshishi no Seisokubunpu Kakudaijokyo Chousa. (Research on the Expansion of the Habitat of Sika Deer and Wild Boar). Retrieved May 12, 2017 from http://www.env.go.jp/press/files/jp/26915.pdf

Nagata, K., 1997, Akita no Kyuketsu Seibutsu: Yamabiru (The Blood Sucking Creature: Yamabiru). Akita: Akitasakigakesinposha. 
Nagy, K., \& Johnson, P. D., eds, 2013, Trash Animals: How We Live with Nature's Filthy, Feral, Invasive, and Unwanted Species. Minneapolis: University of Minnesota Press.

Rigby, K., 2011, Getting a Taste for the Bogong Moth. Australian Humanities Review, $50,77-94$.

Rose, D. B. \& van Dooren, T., 2011, Introduction. Australian Humanities Review, 50, $1-4$.

Sasaki, O., \& Tani, S. (2008). Sika Deer and Wild Boar are Possible Host Animals of the Land Leech Haemadipsa Zeylanica Var. Japonica (Whitman) in Kanagawa Prefecture Based on a PCR-SSCP Snalysis of 28S rRNA. Medical Entomology and Zoology, 59(1), 25-28.

Setoguchi, A., 2009, Gaichu no Tanjo: Mushi kara Mita Nihonshi (The Birth of Pests: A History of Japan by Bugs). Tokyo: Chikuma Shobo.

Simberloff, D., 2013, Invasive Species: What Everyone Needs to Know, Oxford: Oxford University Press.

van Dooren, T., Kirksey, E., \& Münster, U. ,2016, Multispecies Studies: Cultivating Arts of Attentiveness. Environmental Humanities, 8(1), 1-23.

Watanabe, S., 2018, Life with the Yamabiru (Land-Dwelling Leech) After the Failure of a Fence in Rural Japan. Journal of Asian Rural Studies, 2(2), 110-123.

Yamabiru Research Group, 2009, Kanagawaken Iseharashi ni okeru Yamabiru no Seisoku Jokyo Chosa oyobi Yasei Dobutsu Shutsugen Chosa to Satsuhiruzai (Ekizai) no Yagaisanpu ni yoru Satsuhiru Koka Shiken Hokokusho (The Report of the Habita Density Research of Yamabiru and Wild Animals and the Research on the Effectiveness of Expellants Sprayed on the Ground in Isehara City in Kanagawa Prefecture). Tokyo: Kankyobunkasouzokenkyujo.

Yamabiru Research Group, 2017a, Yamabiru Chuiho (Yamabiru Warning). Retrieved May 15, 2017 from http://www.tele.co.jp/ui/leech/region.html

___ - 2017b, Yamabiru towa Donoyona Ikimono nanodeshoka? <Kyuketsu Hoho no Chigai> (What is the Yamabiru?: Differences in Ways of Blood Sucking). $\begin{array}{llll}\text { Retrieved May } & \text { 15, } & \text { from }\end{array}$ http://www.tele.co.jp/ui/leech/yamabiru/suckblood.html

Yamamoto, K., Akasaka, E., Mabuchi, T., Umezawa, K., Ota, Y., Matsuyama, T., Ozawa, A., Fujii, M., Kawabata, H., Watanabe, H., Furuya, Y., Kuroki, T., \& Tani, S., 2005, Shorei Hokoku Kanjokohan to Zenshinshojo wo teishita Hiru Kosho no 1 rei (A Case of a Leech Bite with Erythema Annulare and Constitutional Symptoms). Japanese Journal of Clinical Dermatology, 59(12), 1161-1164. 